\title{
Transatlantica
}

Revue d'études américaines. American Studies Journal

\section{Claire Bruyère. Sherwood Anderson. Le grotesque} tendre.

Paris : Belin, 2001. 128 p.

\section{Anne Ullmo}

\section{OpenEdition}

\section{Journals}

Édition électronique

URL : http://journals.openedition.org/transatlantica/753

DOI : $10.4000 /$ transatlantica.753

ISSN : 1765-2766

Éditeur

AFEA

\section{Référence électronique}

Anne Ullmo, « Claire Bruyère. Sherwood Anderson. Le grotesque tendre. », Transatlantica [En ligne], 1। 2003, mis en ligne le 05 avril 2006, consulté le 29 avril 2021. URL : http://journals.openedition.org/ transatlantica/753 ; DOI : https://doi.org/10.4000/transatlantica.753

Ce document a été généré automatiquement le 29 avril 2021.

\section{c) (i) $९$}

Transatlantica - Revue d'études américaines est mis à disposition selon les termes de la licence Creative Commons Attribution - Pas d'Utilisation Commerciale - Pas de Modification 4.0 International. 


\section{Claire Bruyère. Sherwood Anderson. Le grotesque tendre.}

Paris : Belin, 2001. 128 p.

\section{Anne Ullmo}

1 Claire Bruyère n'aborde pas l'œuvre de Sherwood Anderson selon un ordre chronologique et s'en explique dans l'introduction en précisant que l'œuvre «ne procède pas par étapes claires ». Son ouvrage comprend cinq parties qui exposent dans un style presque andersonien - clair et précis - les traits marquants de l'écriture d'un auteur qu'elle replace avec rigueur dans le contexte littéraire de la Renaissance de Chicago. Dans une première partie intitulée "Le Mythe», l'auteur articule une réflexion qui pourrait ne se nourrir que d'éléments biographiques, autour de la notion de "rupture ", fructueuse dans le cas d'Anderson puisque sa problématique du vide spirituel contraste fort avec celle de la conquête du succès en vogue depuis le XIXeme siècle. Le chapitre II, "Silences éloquents " met quant à lui l'accent sur l'usage andersonien de l'esthétique du grotesque, qui, selon C. Bruyère s'inscrit certes dans une longue tradition artistique mais est déclinée sur un mode personnel par Anderson. Les références à Hugo, Thomas Mann, Poe et d'autres permettent d'affiner la définition du grotesque tout en révélant ce que cette "union des contraires" n'est pas pour Anderson. Le chapitre « Enfances » fait le lien entre la posture naïve et le style oral des récits d'Anderson et la jeunesse des réflecteurs de Mark Twain. L'analyse de Tar: A Midwest Childhood qui met en scène un préadolescent peu sûr de lui permet à l'auteur de souligner que S.Anderson est une fois de plus en rupture avec la culture populaire de l'époque qui renvoie des images de virilité triomphante. Le travail sur la nouvelle moins connue «L'homme qui devint une femme» met en lumière l'univers fantasmagorique des narrateurs andersoniens, leur expulsion douloureuse vers le monde de l'expérience et leur transfert sur le cheval, objet érotique et envers positif de la société. La nouvelle "L'œuf» est le point de départ du chapitre "Résister » qui confirme la place d'Anderson à contre-courant des épopées américaines de l'époque. Si épopée il y a, elle est ici de l'ordre du tragi-comique et du grotesque. Les maladresses de cet écrivain n'occultent pas, nous dit-on, le désir de faire travailler «ce qui gît au dessous ", par opposition à l'entreprise de l'ennuyeux Sinclair Lewis dont le travail est 
de surface. Le rapprochement avec l'ouvrage d'Henry Adams, The Education of Henry Adams, permet à l'auteur d'interroger la place de la femme dans l'œuvre d'Anderson et de réfléchir sur l'impact du social et du politique sur ses derniers récits : l'engagement de l'écrivain dans les années 1930 passe avant tout par une écriture sans concession qui se refuse à embellir le réel. Le dernier chapitre, "L'impuissance créatrice », propose une synthèse sur le style d'Anderson qui ne s'apparente que superficiellement au naturalisme de la fin du XIXe siècle. Les figures de l'incontournable Gertrude Stein ou encore de Cézanne et d'Alfred Stieglitz sont invoquées pour l'influence qu'elles ont exercée sur Anderson: défendre l'authenticité américaine tout en restant ouvert aux influences extérieures semble être le credo de ces artistes qui prônent la simplicité de l'écriture.

2 La mise en contexte est le point fort de cet ouvrage qui ne se paie pas de mots, résume les récits avant de les faire entrer en résonance les uns avec les autres et prend soin de faire état de l'actualité intellectuelle du moment. On pourrait regretter l'absence ici de micro-lecture, mais le format de la collection ne permet pas nécessairement de se livrer à des analyses approfondies des textes. On reviendra néanmoins avec plaisir à la lecture de cet auteur méconnu dont Claire Bruyère sait ici évoquer « le désir de mettre en mots des émotions confuses et violentes ».

INDEX

Thèmes : Recensions

\section{AUTEUR}

ANNE ULLMO

Université Lille 3 